\title{
EL RACISMO Y LA REPRESENTACIÓN SOCIAL DE LO NEGRO ENTRE NINNOS DE PUEBLOS AFROMEXICANOS
}

\author{
Racism and the Social Representation of Blackness Among Children from \\ Afromexican Communities
}

CRISTINA MASFERRER*

Fecha de recepción: 04 de agosto de 2017 - Fecha de aprobación: 16 de noviembre de 2017

\section{Resumen}

Este artículo analiza la representación social que construyen niños de pueblos afromexicanos sobre lo negro o las personas "negras" y examina de qué manera se asocia al racismo. Los resultados se basan en el trabajo de campo realizado en la región con la mayor concentración de localidades afrodescendientes en México, la Costa Chica de Guerrero y Oaxaca, en la cual se desarrollaron diversas estrategias etnográficas con niños de cuatro a catorce años de edad, como entrevistas grupales, talleres de radio y pintura, entre otras. Después de la introducción, se presenta una explicación sobre el contexto en que se realizó la investigación. Posteriormente se exponen los principales elementos de la representación social de niños de localidades afromexicanas sobre lo negro, mostrando en qué medida se vincula al racismo, aunque sin dejar de lado otros aspectos fundamentales como su relación con la construcción social de lugar. Finalmente, se presentan pautas metodológicas para combatir el racismo. Este trabajo busca contribuir a las discusiones antropológicas sobre el racismo a partir de perspectivas teóricas y propuestas metodológicas interdisciplinarias.

Palabras clave: racismo, afrodescendientes, niñez, lo negro, México

\section{Abstract}

This paper analyzes the social representation of blackness constructed by children from Afromexican villages, and examines how this social representation associates with racism. The results of this study are the product of ethnographic field work carried out in the region of Costa Chica, at the Mexican Pacific coast within the states of Guerrero and Oaxaca, through participant observation, interviews, radio and art workshops with children aged four to fourteen years old. After an introduction, it provides an overview of the main characteristics of this region and the Afromexican communities where the field work was carried out. Afterwards, it analyzes the social representation of blackness showing how it relates with racism, as well as to other important aspects, such as the social construction of place. It also presents some methodological ques to fight against racism in Afromexican villages. This study contributes to the anthropological discussions on racism, from an interdisciplinary perspective.

Keywords: racism; afrodescendants; children, blackness, Mexico

\footnotetext{
* Mtra. en Antropología Social. Profesora-Investigadora en la Dirección de Etnología y Antropología Social del Instituto Nacional de Antropología e Historia (INAH), Ciudad de México, México. El artículo se enmarca en las tesis inéditas de maestría (2014) "Aquí antes se llamaba Poza Verde. Conocimientos de niños de la Costa Chica sobre su pueblo y lo negro", México: CIESAS; y de licenciatura (2017) "La representación social de niños de una localidad afromexicana de Oaxaca sobre las personas "negras", México: UNAM. Correo-e: cristina_masferrer@inah.gob.mx
} 


\section{Introducción}

Serge Moscovici (2014), psicólogo y teórico de la representación social, apuntó "si mis observaciones son correctas entonces todos nuestros "prejuicios", ya sean nacionales, raciales, generacionales o los que sean, solo pueden ser superados alterando nuestras representaciones sociales" (p. 39). Con esta premisa en mente, el objetivo de este trabajo es analizar la representación social de niñas y niños de pueblos afromexicanos $^{1}$ de la región Costa Chica acerca de las "personas negras" e indagar de qué manera se vincula al racismo, para proponer pautas metodológicas que coadyuven a combatir este lacerante fenómeno².

Es pertinente aclarar que de ningún modo busco reducir la diversidad, las contribuciones y la riqueza cultural e histórica de estas personas y poblaciones a la representación social de lo negro, comprendiendo, además, que se trata de una categoría construida política, social, cultural e históricamente (Hall, 2010). Lejos de simplificar esta representación social al racismo, busco analizar cómo se vincula (o no) a este fenómeno. Igualmente, es importante señalar que el racismo es mucho más amplio que un conjunto de representaciones sociales ya que, como indica Wieviorka (2009, p. 13), "el racismo consiste en caracterizar un conjunto humano mediante atributos naturales, asociados a su vez a características intelectuales y morales aplicables a cada individuo relacionado con este conjunto y, a partir de ahí, adoptar algunas prácticas de inferiorización y exclusión".

Así, el racismo es una problemática histórica y estructural compleja que se expresa y reproduce mediante prácticas microsociales consistentes con las macroestructuras de desigualdad racial existentes en el sistema, como lo afirma Philomena Essed (1991). En este sentido, no es mi intención mostrar a los niños con quienes trabajé como culpables ni víctimas de las ideas racistas o prácticas discriminatorias que son parte de esta representación social, sino que pretendo analizar cómo esta representación es consistente con las macroestructuras históricas del racismo. La importancia de analizar un fenómeno que perjudica la dignidad de las personas y menoscaba el ejercicio de sus derechos, descansa sobre la posibilidad de comprender mejor cómo opera, para crear estrategias efectivas para erradicarlo.

Es necesario subrayar que el racismo no es restrictivo de la zona con mayor concentración de población afromexicana. La decisión de trabajar en localidades que se consideran afrodescendientes, se debe a la relevancia de lo negro como parte de los procesos identitarios en la región, así como su vinculación con el desarrollo de la autoestima y la autopercepción de los niños que allí habitan. A este respecto, coincido con Stuart Hall (2010), quien afirmó la importancia de "reconocer que todos nosotros estamos compuestos por múltiples identidades sociales" (p. 327); de allí que reconozca que centrar la atención en lo negro constituye un artificio analítico que no da cuenta de las complejas articulaciones que componen las cambiantes y múltiples identidades sociales de las personas con quienes trabajé. Siguiendo a Hall (2010), todos hemos sido construidos complejamente, "a través de diferentes categorías, diferentes antagonismos, y éstas pueden tener el efecto de localizarnos socialmente en múltiples posiciones de marginalidad y subordinación" (pp. 327-328). Analizar la representación social de lo negro no significa que las identidades sociales de las personas de pueblos 
afromexicanos se limiten a este aspecto, pero considero que se trata de un elemento significativo de entre muchos otros.

El artículo busca contribuir a las discusiones antropológicas sobre el racismo a partir de perspectivas teóricas y propuestas metodológicas interdisciplinarias. Inicia con una explicación sobre el contexto en donde se realizó la investigación. Después, se exponen los principales elementos de la representación social de niños de localidades afromexicanas sobre lo negro, mostrando cómo se vincula al racismo, aunque sin dejar de lado otros aspectos como su relación con la construcción del lugar. Finalmente, presento pautas metodológicas para combatir el racismo.

Se han realizado numerosas investigaciones históricas y antropológicas acerca del pasado y el presente de la población de origen africano en México (Velázquez \& Hoffmann, 2007; Velázquez, 2016). Aunque la infancia afromexicana ha recibido menos atención, recientemente se han realizado importantes investigaciones, como las de Citlali Quecha (2011a, 2011b, 2015, 2016), sobre las dinámicas generadas a partir de la migración de los padres de niños de localidades afrodescendientes de Oaxaca. El tema de la crianza en comunidades afromexicanas fue abordado por el etnohistoriador Gonzalo Aguirre Beltrán (1985 [1958]) y, posteriormente, por Cristina Díaz (2003). Amaranta Castillo (2000) analizó los estereotipos y las relaciones interétnicas entre "mixtecos", "mestizos" y "afromestizos" en un municipio de Oaxaca, e incluyó a niños de sexto grado de primaria. Asimismo, en trabajos propios he estudiado la infancia de origen africano en el periodo virreinal y en localidades afromexicanas contemporáneas (Masferrer, 2013, 2014, 2016a, 2017).

\section{La investigación en contexto}

En la época virreinal los aportes económicos, sociales, culturales y políticos de africanos $y$ afrodescendientes fueron significativos en todas las regiones de Nueva España. Después de la Independencia esta población siguió siendo relevante, pero a lo largo del siglo XIX la ideología del mestizaje, el racismo pseudocientífico y el emergente proyecto de nación que se consolidaría en el siglo XX, negaron la participación de las personas de origen africano en la construcción del país, orillándoles a la invisibilización. Por ello, uno de los reclamos de las organizaciones civiles negras o afromexicanas que han ido naciendo desde la década de 1990, es el reconocimiento constitucional e histórico, así como la visibilidad estadística (Lara, 2010; Hoffmann \& Lara, 2012; Velázquez \& Iturralde, 2016). Ello ha derivado en diversas acciones, por ejemplo, que el Instituto Nacional de Estadística y Geografía (INEGI) incluyera una pregunta de autorreconocimiento para esta población en la Encuesta Intercensal de 2015.

En dicho instrumento se confirma la presencia de personas afrodescendientes, afromexicanas o negras en todas las entidades de México, aunque en términos porcentuales destacan Guerrero (6.5\%), Oaxaca (4.9\%) y Veracruz (3.3\%). En cambio, la mayoría de los municipios con $10 \%$ o más de población afromexicana se ubican en la Costa Chica (INEGI, 2017), región costera entre el Océano Pacífico y la Sierra Madre del Sur que abarca parte de Guerrero y Oaxaca; en algunos de ellos, las personas afrodescendientes representan entre 30\% y 84\% (INEGI, 2017). También hay que subrayar la significativa presencia de personas indígenas (mixtecos o ñuu savi, chatinos o kitse cha'tnio, 
amuzgo o nn'anncue y tlapanecas o mepha'a, entre otros), con quienes durante siglos han convivido, compartido y reconstruido sus prácticas culturales.

De acuerdo con Gloria Lara (2012), en la región Costa Chica de Oaxaca se pueden identificar microrregiones y zonas. El siguiente cuadro resume algunas características de las zonas conocidas como Llanada (lomerío suave que se extiende hacia Guerrero), Costera, Baja, Media y Alta. Aunque se advierte la predominancia de poblaciones indígenas, afromexicanas o "mestizas", conviene subrayar la heterogeneidad de las zonas y los intercambios históricos que han tenido estos grupos (Lara, 2012).

\section{Cuadro 1. Zonas de la Costa Chica de Oaxaca}

\begin{tabular}{|c|c|c|c|}
\hline Zonas & Características ecológicas & Actividades productivas & Poblaciones \\
\hline Llanada & $\begin{array}{l}\text { Lomerío suave, praderas } \\
\text { naturales, suelos arcillosos. } \\
\text { Llanura. }\end{array}$ & $\begin{array}{l}\text { Agricultura de temporal: } \\
\text { Jamaica, ajonjolí, maíz y } \\
\text { frutales. Ganadería } \\
\text { semi-intensiva }\end{array}$ & $\begin{array}{l}\text { Alta presencia } \\
\text { afromexicana. } \\
\text { Pob. indígena: } 1.5 \%\end{array}$ \\
\hline Costera & $\begin{array}{l}0-10 \text { msnm. } \\
\text { Humedales, lagunas, } \\
\text { manglar, dunas costeras y } \\
\text { pastizales naturales. }\end{array}$ & $\begin{array}{l}\text { Ganadería extensiva. } \\
\text { Agricultura de humedad. } \\
\text { Cultivos: ajonjolí, maíz, sandía, } \\
\text { melón, plátano, coco. Pesca } \\
\text { ribereña y turismo. }\end{array}$ & $\begin{array}{l}\text { Alta presencia } \\
\text { afromexicana. } \\
\text { Pob. indígena: } 3.1 \%\end{array}$ \\
\hline $\begin{array}{l}\text { Baja } \\
\text { (planicie) }\end{array}$ & $\begin{array}{l}11-250 \text { msnm. } \\
\text { Terrenos generalmente } \\
\text { planos con poca pendiente. } \\
\text { Suelos profundos limosos. }\end{array}$ & $\begin{array}{l}\text { Agricultura intensiva con } \\
\text { mecanización y riego. } \\
\text { Ganadería extensiva e } \\
\text { intensiva. Frutales: coco, } \\
\text { mango, limón, papaya, plátano. }\end{array}$ & $\begin{array}{l}\text { Media presencia } \\
\text { afromexicana. } \\
\text { Pob. indígena: } 13.7 \% \\
\text { Población "mestiza" }\end{array}$ \\
\hline $\begin{array}{l}\text { Media } \\
\text { (pie de } \\
\text { monte) }\end{array}$ & $\begin{array}{l}\text { 251-500 msnm. } \\
\text { Montañas suaves y } \\
\text { pequeños lomeríos. }\end{array}$ & $\begin{array}{l}\text { Agricultura de temporal: maíz, } \\
\text { frijol y frutales. Ganadería } \\
\text { extensiva a mediana escala. }\end{array}$ & Pob. indígena: $49.1 \%$ \\
\hline $\begin{array}{l}\text { Alta } \\
\text { (Sierra) }\end{array}$ & $\begin{array}{l}\text { Mayor a } 500 \text { msnm. } \\
\text { Montaños y pendientes. }\end{array}$ & $\begin{array}{l}\text { Café, maíz, frijol, frutales de } \\
\text { temporada y ganado. }\end{array}$ & Pob. indígena: $49.3 \%$ \\
\hline
\end{tabular}

Fuente: Lara, 2012, pp. 71-72 (con modificaciones).

En este artículo se presentan los resultados del trabajo de campo realizado en Cuajinicuilapa (Guerrero), El Potrero (Oaxaca) y José María Morelos (Oaxaca), localidades ubicadas en las zonas Llanada, Costera y Baja, respectivamente. En diversas estancias entre 2011 y 2015, realicé entrevistas grupales e individuales, talleres de radio y de pintura con niños, talleres con maestros y etnografía educativa en cinco escuelas, entre otras estrategias de investigación con personas de todas las edades. No obstante, este artículo se centra en la construcción y representación 
social de lo negro a partir de entrevistas individuales y grupales, talleres de radio y de pintura en los cuales participaron 172 niños (87 varones y 85 niñas), cuyas edades oscilaron entre los cuatro y los catorce años. Sólo ocho cursaban el preescolar, mientras que el resto se encontraba en alguno de los seis grados del nivel Primaria ${ }^{3}$, con lo cual se abarcó a niñas y niños de nueve instituciones educativas de la región ${ }^{4}$.

Las tres localidades de estudio se ubican en la región Costa Chica de Guerrero y Oaxaca de México, sin embargo, cada una de ellas tiene características particulares que es preciso señalar, al menos de manera breve. Cuajinicuilapa es la cabecera del municipio con el mismo nombre. De acuerdo a la Encuesta Intercensal $2015,56.4 \%$ de la población del municipio se considera afrodescendiente, $34.7 \%$ se autoadscribe como indígena y $6.3 \%$ de las personas mayores de 3 años habla alguna lengua originaria (www.beta.inegi.org.mx). En cambio, José María Morelos y El Potrero son agencias del municipio de Santa María Huazolotitlán, cuya cabecera lleva el mismo nombre y se caracteriza por ser mayoritariamente mixteca. A diferencia de otros municipios de Oaxaca, en Huazolotitlán son muy cercanos los porcentajes de personas que se reconocen como afrodescendientes $(49.4 \%)$ y como indígenas $(45.3 \%)$, o que hablan alguna lengua originaria (30.9\%).

Aunque Morelos y El Potrero son considerados pueblos afromexicanos, es importante subrayar la presencia de personas mixtecas y de otros orígenes, además de la dependencia histórica que ambos tienen con respecto a la cabecera Santa María Huazolotitlán en términos político-administrativos y de comunicación ${ }^{5}$ (Masferrer, 2014, pp. 73-75). Por su parte, la ciudad de
Cuajinicuilapa, con más de 10 mil habitantes, es considerada una de las cunas de la población afromexicana (Hoffmann, 2007a). Además, allí se encuentra el Museo de las Culturas Afromestizas, primero del país en dedicarse especialmente a la historia y el presente de estas comunidades; desde hace veinte años México Negro AC y el Taller Cultural Cimarrón, entre otras organizaciones, han tenido un papel destacado en ella y en 2016 la UNESCO le declaró Sitio de Memoria de la Esclavitud y las Personas Afrodescendientes. En José María Morelos, las acciones de las organizaciones AFRICA AC, la Casa de Cultura de Morelos, entre otras, han sido visibles desde hace años. En cambio, en El Potrero han tenido mucho menor incidencia.

Si se retoma la propuesta de Lara (2012) sobre la Costa Chica, podemos decir que Cuajinicuilapa se localiza en la microrregión Llanada-Pinotepa-Cuajinicuilapa, y en la zona de la Llanada. José María Morelos se ubica en la microrregión de Pinotepa Nacional y en la zona caracterizada como Baja, de acuerdo a su producción agrícola y a su altitud. Por su parte, El Potrero se encuentra en la zona Costera y en la microrregión de Pinotepa Nacional.

Cuajinicuilapa es cabecera municipal y representa un punto importante en la microrregión a la cual pertenece y, además, se ubica sobre la carretera federal. Por su parte, José María Morelos es una agencia municipal de poco más de 2 mil habitantes, y constituye un centro productivo fundamental que participa activamente en la producción y distribución de papaya a nivel regional, nacional y transnacional. El Potrero, en cambio, es una agencia de policía que no llega a 300 habitantes y que depende económicamente del pueblo afromexicano José María Morelos. 


\section{Mapa 1. Principales localidades en la investigación}

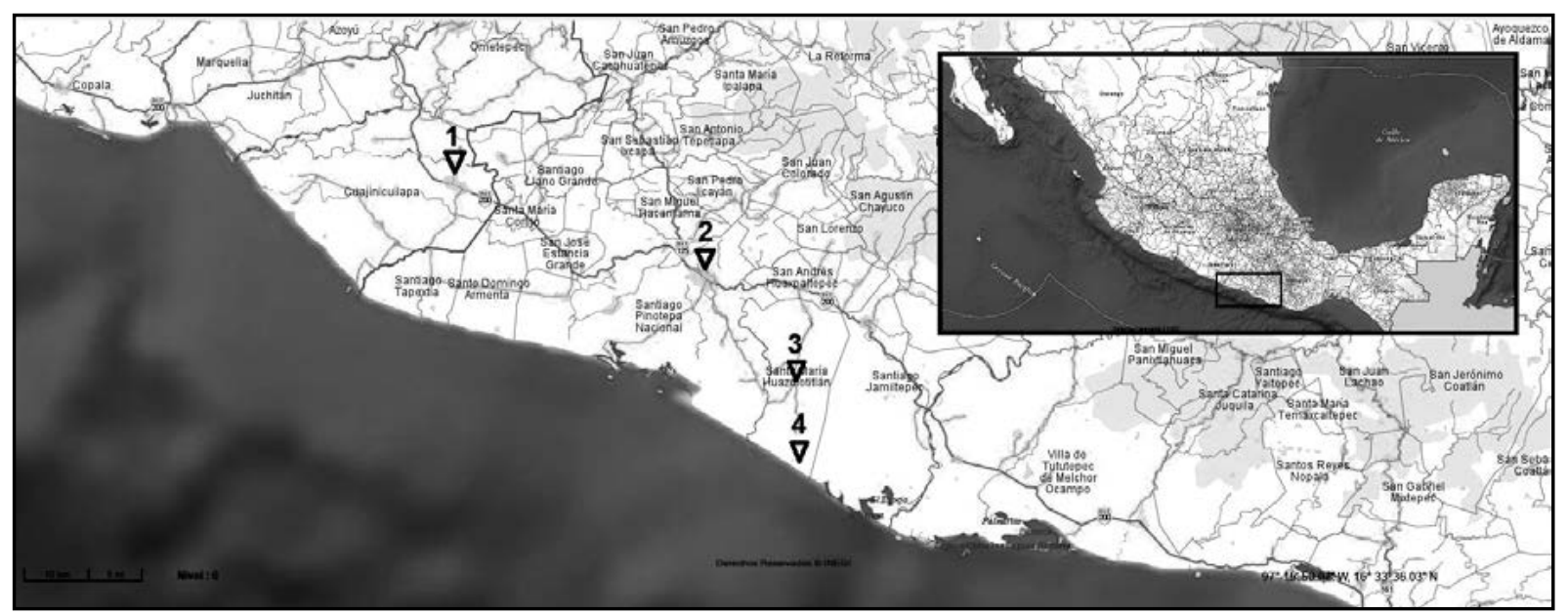

Fuente: Elaboración propia a partir de INEGI, http://gaia.inegi.org.mx/mdm6

Notas: $\nabla$ 1. Cuajinicuilapa, Guerrero. 2. Pinotepa Nacional, Oaxaca. 3. José María Morelos, Oaxaca. 4. El Potrero, Oaxaca.

Así, la importancia administrativa, demográfica y económica de Cuajinicuilapa, contrasta con Morelos y El Potrero. Sin embargo, es necesario subrayar el papel central de Morelos en términos económicos y productivos, a pesar de que la dependencia de Morelos y El Potrero a una cabecera municipal mixteca es un elemento notable al analizar las dinámicas de estas localidades, sus modelos étnicos y los procesos de identificación asociados al "lugar", en tanto categoría geográfica. Al analizar casos en Guerrero, Oaxaca y Veracruz, Odile Hoffmann (2007a, 2007b) caracterizó este fenómeno como el "efecto-lugar", concepto que no se limita a las características de la localidad, sino que es producto de "su inscripción e interacciones múltiples con otros niveles" y "se mantiene y evoluciona gracias a la resignificación de las diferencias desde otros ámbitos" (Hoffmann, 2007a, p. 106).
A partir de esta propuesta interpretativa, Hoffmann (2007a) asegura que Cuajinicuilapa se desarrolló como un pueblo de mestizos y morenos, sin una referencia tan notable a los blancos como ocurrió en otros lugares, por ejemplo, en Pinotepa Nacional. Esta configuración histórica condujo "a un dispositivo político local de tipo horizontal, por lo menos en su lógica formal, en el cual la competición local tiene lugar entre los mestizos y afromestizos presentes, incluidos los pocos blancos e indígenas recién inmigrados" (Hoffmann, 2007a, p. 104). Se trata de un modelo "mestizo"6 donde "la élite local (comercial, profesionales y profesores), asume el discurso de la identidad negra o afromestiza, bajo el ángulo del "rescate cultural" promovido por las instituciones [y en la cual] Cuajinicuilapa aparece como la cuna afromestiza" (Hoffmann, 2007a, p. 104). 
En cambio, el modelo "étnico" de Oaxaca se caracteriza por la representación de "tres razas"', similar a la división de castas o calidades del periodo virreinal, donde los "blancos", los "indígenas" y los "negros" ocupan una posición específica y diferenciada (Hoffmann, 2007a). El análisis de esta investigadora se centra en Pinotepa Nacional, ciudad que concentra una inmensa importancia económica, política y de comunicación en la región Costa de Oaxaca, así como en la microrregión en la cual se inscriben Morelos y El Potrero, actuando como un centro-mercado fundamental (Lara, 2012).

En términos generales este modelo "étnico" es aplicable a estas dos localidades oaxaqueñas, sin embargo, la composición indígena de Huazolotitlán permite sugerir que en José María Morelos la competencia y las fronteras étnicas se construyen sobre todo entre "dos razas", desplazando el papel de la élite "blanca" o "mestiza" hacia lugares como Pinotepa Nacional (relevante, pero a cierta distancia). Por su parte, la posición marginal de El Potrero, su dependencia económica a Morelos y la presencia de unas cuantas familias mixtecas allegadas recientemente, remite a una competencia entre dos localidades afromexicanas (aunque ambas dependan de la cabecera municipal indígena y tengan como referente significativo la élite "mestiza" de Huazolotitlán y la "blanca" o "mestiza" de Pinotepa).

El "efecto-lugar" de las localidades donde he trabajado tiene un papel importante en la manera en que los niños construyen representaciones sociales sobre lo negro y las formas en que éstas se relacionan con el racismo, no obstante, también es posible identificar elementos comunes de la representación social de lo negro entre niñas y niños de estas tres localidades, como hago a continuación, procurando visibilizar las diferencias que son más significativas.

\section{La representación social de lo negro y el prejuicio racista entre niñas y niños}

Las representaciones sociales trascienden la esfera de las simples opiniones, imágenes y actitudes, más bien, son sistemas cognoscitivos (Farr, 1984), formas de conocimiento y pensamiento socialmente elaboradas y compartidas (Jodelet, 1984). De acuerdo con Moscovici (Duveen \& Lloyd, 2003), son sistemas de valores, ideas y prácticas que establecen un orden que permite que los individuos se orienten en su mundo social y material, además de que posibilitan la comunicación mediante el aporte de dos códigos, uno para el intercambio social y otro para clasificar de manera inequívoca los aspectos de su mundo, de su historia individual y grupal.

Las representaciones sociales siempre son de algo y de alguien; son convencionales y prescriptivas; se producen, recrean y modifican en las interacciones y los intercambios comunicativos; pertenecen a un contexto social, cultural, geográfico e histórico, por lo que tienen un origen y un desarrollo histórico, y; conforman el entorno pensante de los individuos (Masferrer, 2017, con base en Moscovici, 2014; Jodelet, 1984; Farr, 2003; Duveen \& Lloyd, 2003; Castorina \& Kaplan, 2003). Este entorno pensante no es algo externo, sino que, siguiendo la psicología histórico-cultural, existe una interacción dialéctica entre el medio sociocultural y la conciencia del sujeto (Hernández, 2006).

Por su parte, Denise Jodelet (1984) definió las representaciones sociales como:

Imágenes que condensan un conjunto de significados; sistemas de referencia que nos permiten interpretar lo que nos sucede, e incluso, dar un sentido a lo inesperado; categorías que sirven para clasificar las circuns- 
tancias, los fenómenos y a los individuos con quienes tenemos algo que ver; teorías que permiten establecer hechos sobre ellos (p. 472).

Con base en esta definición, se identificaron las categorías, las imágenes y las teorías sobre las personas negras, entre niños de pueblos afromexicanos, para después evaluar cómo esta representación social se vincula a actitudes positivas o a prejuicios, estereotipos, estigmas y categorías asociadas al racismo.

A partir de la investigación se encontró que los principales términos que se emplean para nombrar a las "personas negras" son "negros" y "morenos", sin embargo, en algunos casos la palabra "prietos" también fue relevante. En Cuajinicuilapa, donde hay una importante incidencia de organizaciones civiles, los términos "afromexicanos" y "afromestizos" también fueron de suma relevancia. Otras palabras empleadas para clasificar a los individuos fueron "güeros", "blancos", "rubios", "indígenas" o "indios".

Al respecto de los términos "negros" y "morenos" cabe apuntar que muchas veces pueden emplearse como sinónimos, aunque los niños reconocen diferencias en sus significados. Esta aparente contradicción muestra la complejidad de los procesos de identificación pues se trata de palabras con significados equívocos. En Morelos, durante un taller de radio, una niña de quinto grado explicó: "porque los negros son los más morenos, y los morenos son los que tienen más claro el tono de su piel", mientras que otra niña más pequeña respondió: "a los morenos también les dicen negros” (enero 2013). Así, estos términos se vinculan y muchas veces pueden emplearse como sinónimos, aunque en cierta medida su significado depende del verbo con el cual se acompañe y la posición que ocupa en la oración. Por ejemplo, en otra entrevista colectiva del mismo pueblo, uno de los niños señaló que "el moreno está más claro", y otro completó diciendo "y el negro está bien prieto, prieto". En esta última frase, las palabras "está bien prieto" ayuda a definir a la persona negra, aunque el hecho de utilizar el verbo "estar" remite al color o tono de piel y tiene implicaciones que se explican más adelante. Además, la insistencia ("bien prieto, prieto") pudiera remitirnos a un estigma sobre lo negro, como se discute posteriormente, concepto que hace referencia a una marca física o simbólica a la que de manera histórica y social se la atribuye un carácter negativo (Goffman, 2006) ${ }^{8}$.

En El Potrero, donde se hizo una comparación a partir del grado educativo de los niños, se encontró que entre aquellos de grados escolares menores se emplearon otras palabras como "güeros", "blancos" e "indígenas" al hacer referencia a las personas negras; ello se interpretó como evidencia de los mecanismos de anclaje y de objetivación de la representación social, los cuales se complementan dialécticamente. El primero implica reproducir las nociones abstractas en imágenes, "descubrir la calidad icónica de una idea o de un ser impreciso" (Moscovici, 2014, p.45). Por su parte, el anclaje hace referencia "a la integración cognitiva del objeto representado dentro del sistema de pensamiento preexistente y a las transformaciones derivadas de este sistema" (Jodelet, 1984, p.486).

Al respecto de las categorías que clasifican a los individuos, es importante señalar su complejidad, así como el hecho de que no se trata de categorías restrictivas, sino que en ocasiones se puede ser "negro" e "indio" 
a la vez. La Encuesta Intercensal (INEGI, 2017) reveló que el $21.5 \%$ a nivel nacional se considera indígena y afrodescendiente a la vez; porcentaje que incrementa a $66.4 \%$ en los municipios con $10 \%$ o más de población afrodescendiente. A nivel local, esta noción también está presente entre niñas y niños, lo que confirma la relevancia de considerar "los márgenes de las clasificaciones y las categorías (ser a la vez negro y mestizo, indio y negro), las desviaciones, las contradicciones asumidas, las subversiones del orden racial" (Velázquez \& Hoffmann, 2007, p. 65).

Otro elemento de la representación social lo conforman las imágenes que condensan conjuntos de significados sobre las personas negras. En términos generales, una de las imágenes recurrentes al hablar de gente negra y morena es que se trata de personas de su propio pueblo o de otros de la región. Además, en Morelos y en Cuajinicuilapa fue común la asociación entre estas personas y la esclavitud, así como el haber llegado en barcos o desde África, mucho tiempo atrás, lo que también reitera la relación histórica entre estas personas y el lugar.

En El Potrero, estas imágenes fueron más amplias entre los niños de grados escolares menores, quienes las asocian a personas de diferentes edades que realizan actividades positivas y que tienen atributos diversos; por ejemplo, mencionaron que se trata de personas de diferentes edades que trabajan y caminan y que pueden ser ricas. En cambio, fue notorio que los niños de grados escolares más avanzados asociaron a las personas negras con personas mayores, lo que evidencia el establecimiento de una distancia hacia ellas $y$, por tanto, una menor identificación con las mismas; ello es congruente con los atributos negativos que los niños de grados educativos más avanzados (4ำ a $6^{\circ}$ de primaria, aproximadamente entre 9 y 12 años de edad) asociaron a dichas personas, como la pobreza o la fealdad. Estos atributos negativos estuvieron presentes en las tres localidades de estudio, aunque en Morelos una niña de quinto grado contradijo la asociación con la pobreza: "no es cierto que los morenos son pobres porque el presidente de los Estados Unidos, Barack Obama, es rico", y de inmediato otras voces complementaron: "y es moreno", "sí es cierto", "es negro" (Masferrer, 2014, p. 416). Además, la fuerza física también fue parte de las imágenes que los niños tienen sobre estas personas.

Por otro lado, entre los niños de estas localidades afromexicanas se identificaron seis teorías sobre lo negro (cuadro 2) ${ }^{9}$. A partir de las entrevistas realizadas con personas adultas, fue posible encontrar las mismas teorías, no obstante, el trabajo centrado en niñas y niños muestra cómo varía la preponderancia de las teorías en cada grupo de edad, aunque todas pueden estar presentes en un mismo grupo etario. 


\section{Cuadro 2. Principales teorías infantiles sobre las personas negras}

\section{LO NEGRO COMO}

Condición intemporal de la esencia de la persona.

2. Una condición transitoria, no permanente o reversible.

Algo que se debe a razones climáticas.

4. Característica con la que se nace, o una forma de ser desde el nacimiento.

5. Aspecto que denota un vínculo familiar o una familia de pertenencia.

6. Lo negro como una característica colectiva o general de la población de un lugar de pertenencia o procedencia.

Fuente: Elaboración propia.

Las primeras dos teorías se distinguen por el uso diferenciado de los verbos "ser" o "estar". Sobre estos verbos, Carballera y Sastre (1991) explican que la diferencia entre ellos suele radicar en que "ser" se asocia a cualidades permanentes 0 intemporales, mientras que "estar" se considera el verbo de la temporalidad, refiriéndose a lo transitorio o accidental y determinado "por alguna circunstancia" (p.300) ${ }^{10}$. Este detalle es bastante significativo, ya que la utilización del verbo "ser" por parte de los niños expresa la comprensión de lo negro como una condición de la esencia de la persona, permanente e intemporal o duradera (Masferrer, 2014, 2017; sobre el uso de estos verbos en mujeres adultas, véase Moreno, 2012).

\section{Ejemplos}

Uso del verbo ser ("son negros", "soy negra")

Verbo estar, entre otros.

El sol, jugar en la playa o asolearse.

Ejemplos: "está prieto", "me vas a pegar lo prieto", "se pone negro."

"Naciste así", "yo salí así".

"Vienen de familia"; "así es su papá, o su mamá, o sus abuelos".

El lugar puede ser un pueblo, una región o un continente ("somos los negros de la costa", "todos los de aquí de Morelos somos negros", "de África").
En cambio, otros verbos empleados por los niños de localidades afromexicanas remiten a la teoría de que lo negro es una condición momentánea o accidental ("está negro", "se pone negro"); en ocasiones, vinculándolo a un estigma, como si lo negro fuera algo contagioso ("me vas a pegar lo prieto"). Asimismo, lo negro apareció como una característica reversible: "a veces unos cuando salen negros cuando nacen, se ponen blancos... porque de ahí cuando van creciendo se van poniendo blancos" (Felipe Echeverría, cuarto grado, taller de radio, 2012). Esta reversibilidad fue recurrente en los comentarios de niñas y niños, y también varios adultos lo mencionaron. 
En general, entre los niños de primero y segundo de primaria son más comunes las teorías 1, 4 y 5, es decir, lo negro como algo permanente, con lo que se nace y que establece un vínculo de parentesco ya que se hereda de algún familiar. En cambio, entre los niños de tercer grado de primaria en adelante, destacan las teorías 2 y 3 , que refieren a lo negro como algo no permanente que se explica por motivos climáticos; aunque es importante señalar que también están presentes las teorías 1 y 4,5 y 6 . Como se muestra más adelante, la manera en que cambia la predominancia de estas teorías dependiendo de la edad, también se relaciona con un incremento de estereotipos, prejuicios racistas y la construcción de lo negro como estigma (cuadro 3).

En las localidades donde las organizaciones civiles han tenido más incidencia, la sexta teoría es bastante relevante, sobre todo entre los niños de los últimos grados de Primaria; esta es una diferencia notable con respecto a los niños de El Potrero. Así, en Morelos y Cuajinicuilapa uno de los aspectos más significativos de lo negro es su asociación o vinculación a su pueblo, lugar de pertenencia y procedencia, o bien, a otros de la región. Por tanto, la vinculación de lo negro con estos lugares, en tanto construcciones sociales, ideológicas y ecológicas del espacio, pudiera deberse a las acciones de las organizaciones civiles afromexicanas, así como a una mayor infraestructura (más escuelas, museos, carreteras, mayor cercanía con los centros-mercado). También hubo casos donde mencionaron a África como un continente donde hay personas negras, aunque no fue algo generalizado y algunos niños de mayor edad desconocieron a este continente como un lugar de origen o procedencia de "personas negras".
Por tanto, no sólo el lugar es central en la construcción de la representación social de lo negro, sino que lo negro también tiene un papel fundamental en la construcción social del lugar por parte de niñas y niños. Ello nos permite asegurar que lo negro no se reduce a un rasgo corporal visible como el tono de piel, sino que integra aspectos sociales, culturales e históricos atribuidos al espacio. Al respecto hay que considerar que el lugar no se define en términos de sus límites físicos, sino que puede imaginarse como momentos articulados de redes de relaciones sociales y significados, en un locus particular (Massey, 1994). De acuerdo con Butz y Eyles (1997), el lugar es una construcción social, ideológica y ecológica, ya que se construye a partir de las relaciones e interacciones sociales, se vincula a símbolos y significados construidos colectivamente y se ello se sustenta materialmente a partir del ambiente; asimismo, se construye un sentido de lugar a partir del apego a éste.

\section{Prejuicios racistas y actitudes positivas}

El proceso de categorización es imprescindible para el pensamiento humano y las categorías favorecen la formación de prejuicios mediante los procesos de asimilación y contraste, pero las categorías no necesariamente son opiniones negativas, como los prejuicios, de modo que para comprender los motivos por los que determinados estereotipos y prejuicios se imponen sobre ciertas poblaciones es necesario analizar su dimensión histórica, social, cultural y política. Algunas de las consecuencias de la formación de prejuicios, es que las personas pensarán e interpretarán su entorno a partir de ellos, reiterándolos mediante procesos conocidos como atención, percepción y memoria selectivas, y 
el fenómeno llamado profecía autocumplida (Worchel, Cooper, Goethals \& Olson, 2002; Billig, 1985; Plous, 2003).

El prejuicio es una actitud u opinión negativa hacia un grupo de personas, o hacia una persona por pertenecer a dicho grupo (Allport, 1954); y puede vincularse a estereotipos, estigmas, discriminación y racismo, pero se trata de fenómenos diferentes. Los estereotipos son ideas que generalizan y exageran ciertos aspectos de manera equivocada (Billig, 1985; Conapred, 2008; Plous, 2003; Restrepo, 2012). El estigma es una marca física o simbólica a la que socialmente se le atribuye un carácter negativo y desacreditador (Goffman, 2006; Conapred, 2008). Por su parte, la discriminación es una conducta que tiene como consecuencia, intencional o no, excluir y negar o menoscabar los derechos humanos (Billig, 1985; Conapred, 2008). En cambio, el racismo implica una serie de prácticas de rechazo, negación y exclusión fundamentadas en ideologías que se basan en la creencia de que los seres humanos nos dividimos en razas; entendiéndolas como grupos biológicos que comparten y heredan ciertos rasgos corporales visibles, características intelectuales, comportamentales y culturales, mismos que además evidenciarían una supuesta jerarquía entre ellas. Como afirma Restrepo (2012), el racismo es una forma de discriminación articulada en torno a lo racial; de modo que implica un acto de diferenciación y un ejercicio de exclusión hacia personas o colectivos a las cuales social e históricamente se les ha atribuido ciertas características raciales (aunque las razas no existen biológicamente; Ramírez, 2007, 2009).
Más allá de la definición y diferencia entre estos conceptos, lo que es realmente significativo es su carácter histórico y estructural, ya que su presencia en las interacciones microsociales y el hecho de que a partir de ellas se reproduzcan, no puede comprenderse sin su correlato en estructuras macrosociales configuradas históricamente (Essed, 1991). Así, la representación social de los niños de estas localidades sobre lo negro implica -siguiendo a Vygotski (2006, pp. 93-94) - la internalización de "actividades socialmente arraigadas e históricamente desarrolladas", proceso caracterizado por "una serie de transformaciones" que en un primer momento van de lo interpsicológico a lo intrapsicológico pero que, por su carácter dialéctico, no pueden explicarse mediante reduccionismos dualistas ni adultocéntricos (Qvortrup, 2011; Szulc, 2006; James \& Prout, 1997; Toren, 1993).

Los resultados de la investigación muestran que el prejuicio forma parte de la representación social sobre las personas negras de los niños de estas tres localidades afromexicanas, aunque su predominancia depende del nivel de acción de las organizaciones civiles, entre otros factores, como la edad y el grado escolar que cursen. En el poblado donde las organizaciones no han tenido mayor peso, el prejuicio racista se expresa en mayor medida, o con menor inhibición, en los niños de grados escolares intermedios.

En todos los casos se encontró que el prejuicio se expresa en estereotipos, estigmas, la evocación de conductas discriminatorias y el uso de categorías raciales. En cuanto a los estereotipos y el estigma (Goffman, 2006), fue recurrente que se hicieran comentarios negativos sobre el tono de piel, empleando apodos relacionados con ello; incluso se expresaron frases que denotan 
lo negro como algo contagioso, como ya se dijo. Asimismo, fue recurrente, sobre todo entre los niños de más edad, que se hiciera referencia a las prácticas de discriminación en que se ven involucradas estas personas, por ejemplo, al señalar que hay quienes no quieren juntarse o sentarse con ellos (Masferrer, 2016b), o quienes utilizan estas palabras como insulto, "ofende decir negro", "es como una grosería", "cuando dicen negro es como si se estuvieran diciendo un apodo". Cuando se hizo mención a este tipo de actos, muchas veces se expresó empatía.

Por otro lado, el uso de la palabra y el concepto de raza fue común en todos los casos, aunque a partir de tercer grado de primaria se le utiliza con mayor frecuencia. Los niños mencionan a personas blancas o güeras, pero por lo general emplearon la palabra raza para referirse a los indígenas y los negros o morenos; tratándose de grupos definidos por aspectos corporales (piel y cabello), culturales (idioma y vestimenta), sociales (relaciones e interacciones) o geográficos (lugares de procedencia). De manera excepcional se empleó esta palabra como sinónimo de familia sin asociarse al racismo, lo cual es importante ya que, de acuerdo con Eduardo Restrepo (2012): "no hay que confundir la presencia o ausencia de una palabra con la presencia o ausencia de un concepto" (p.155).

Algunos niños afirmaron que la raza significaba "el color de la piel" y se vinculaba con la sangre "la raza ya la llevan en la sangre y ya que cuando nacen salen de ese color" (entrevista colectiva, sexto grado). Sin embargo, otros mostraron la importancia de criterios culturales, sociales o geográficos; tal fue el caso de Isabela Torres (cuarto grado), quien explicó que los negros son de una raza, son morenos y hablan "los idiomas de los negros", mientras que los indígenas pueden ser morenos o blancos y hablan mixteco, aunque también conozcan "los idiomas de los negros" (taller de radio, 2013). Sobre el significado de la palabra "raza" abundó: "Que a veces donde ellos viven todo su pueblo puede ser negro y ellos pueden ser de su raza pues, de ahí donde viven, o a veces los que son de otro pueblo son blancos y desprecian, este, la raza negra" (Isabela Torres, taller de radio, 2013).

La importancia que tiene la familia y el lugar de procedencia en los conocimientos infantiles sobre lo negro y la raza nos remite al concepto colonial de casta, ampliamente utilizado en Nueva España. De acuerdo a diccionarios de los siglos XVII y XVIII, tanto la raza como la casta eran entendidas como el linaje al cual se pertenecía (González, 2011), además, podía referirse a la calidad ("casta mulata", "casta mestiza"), así como a la nación, grupo étnico o región de procedencia ("casta angola", "casta benguela", "casta japón"). No obstante, si consideramos que en la región circulan ideas que asocian a los negros con los simios, como si hubieran quedado en un nivel evolutivo previo, así como la recurrencia de estereotipos sobre el comportamiento, la sexualidad, la fortaleza o la poca inteligencia de las personas dependiendo de la "raza" que se les atribuye, es posible suponer que estamos frente a ideas heredadas del racismo pseudocientífico (Masferrer, 2014, 2016b).

A pesar de la prevalencia y lo notorio del prejuicio, el aspecto más sobresaliente de esta representación social -y que los niños aprenden primero-, se centra en considerar a las personas negras como pertenecientes al contexto cotidiano y en comprender a lo negro como parte de la esencia y la familia de las personas, consti- 
tuyendo un elemento permanente o duradero de las mismas. Dado que los niños expresan el prejuicio asociado a esta representación cuando tienen más edad, es de suponer que lo aprenden en un segundo momento. Para Christina Toren (1993) el primer aspecto y el más sobresaliente constituye la dimensión afectiva que los adultos comunican a partir de su praxis corporal y otras actitudes no verbales, mientras que lo que se aprende posteriormente se vincula más con la comunicación verbal.

Las actitudes positivas que son parte de la representación social sobre las personas negras de los niños de estos poblados se expresan en autoadscripción, actividades positivas, atributos positivos y empatía. En la localidad El Potrero, las actitudes positivas que forman parte de la representación social sobre las personas negras fueron comunes entre aquellos de grados escolares menores, pero disminuyeron dramáticamente en el tercer grado de primaria (aproximadamente a los 8 o 9 años). En cuanto a la autoadscripción, casi en todos los casos se reconoce la presencia de personas negras en la localidad y por lo general los niños señalan quiénes lo son sin mayor dificultad, en cambio, al momento de indagar acerca de la autoadscripción, fue más común entre los niños de menor edad y entre los niños de los poblados donde las organizaciones han tenido un trabajo significativo, como Morelos y Cuajinicuilapa. Así, la autoadscripción se dificulta conforme el prejuicio se incorpora a la representación social sobre las personas negras. Además, en los pocos casos donde comparé la elaboración de pinturas sobre personas negras con las entrevistas grupales, encontré que la medida en que el "color" de piel se enuncia verbalmente como un atributo de las "personas negras", menor es el uso de colores obscuros (negro o café) en las representaciones gráficas de las mismas. 
Cuadro 3. Representación social de lo negro, racismo y edad

\begin{tabular}{|c|c|c|}
\hline \multicolumn{3}{|c|}{ EDAD } \\
\hline $\begin{array}{l}1^{\circ} \text { y } 2^{\circ} \text { de primaria } \\
(6-8 \text { años aprox.) }\end{array}$ & $\begin{array}{l}3^{\circ} \text { y } 4^{\circ} \text { de primaria } \\
(8-10 \text { años aprox.) }\end{array}$ & $\begin{array}{l}5^{\circ} \text { y } 6^{\circ} \text { de primaria } \\
(10-12 \text { años aprox.) }\end{array}$ \\
\hline $\begin{array}{l}\text { Categorias que clasifican a los } \\
\text { individuos }\end{array}$ & \multicolumn{2}{|c|}{ Categorías que se refieren a personas "negras" } \\
\hline $\begin{array}{l}\text { Negros } \\
\text { Morenos } \\
\text { Indígenas } \\
\text { Indios } \\
\text { Güeros } \\
\text { Blancos }\end{array}$ & \multicolumn{2}{|l|}{$\begin{array}{l}\text { Negros } \\
\text { Morenos } \\
\text { Prietos } \\
\text { Afromestizos } \\
\text { Afromexicanos }\end{array}$} \\
\hline \multicolumn{3}{|c|}{ IMÁGENES QUE CONDENSAN CONJUNTOS DE SIGNIFICADOS } \\
\hline $\begin{array}{l}\text { Personas de la localidad propia, } \\
\text { o de otras de la región. } \\
\text { Personas de diferentes edades. } \\
\text { Ricos o pobres. } \\
\text { Fuertes. } \\
\text { Actividades cotidianas. }\end{array}$ & \multicolumn{2}{|c|}{$\begin{array}{l}\text { Personas de la localidad propia, o de otras de la región. } \\
\text { Personas mayores. } \\
\text { Pobreza. Fealdad. } \\
\text { Esclavitud. } \\
\text { África. }\end{array}$} \\
\hline \multicolumn{3}{|c|}{ TEORIAAS PREPONDERANTES SOBRE LO NEGRO } \\
\hline $\begin{array}{l}\text { 1. Lo negro como condición de } \\
\text { la esencia de la persona e } \\
\text { intemporal. } \\
\text { 4. Característica con la que se } \\
\text { nace, o forma de ser desde el } \\
\text { nacimiento. } \\
\text { 5. Lo negro como un aspecto } \\
\text { que denota un vínculo familiar. }\end{array}$ & $\begin{array}{l}\text { 2. Lo negro como condición } \\
\text { transitoria y reversible. } \\
\text { 3. Lo negro como algo que se } \\
\text { debe a razones climáticas. } \\
\text { Continúan presentes las teorías } \\
1,4 \text { y } 5 \text {. }\end{array}$ & $\begin{array}{l}\text { 6. Lo negro como una } \\
\text { característica colectiva o } \\
\text { general de la población de } \\
\text { un lugar de pertenencia o } \\
\text { procedencia (pueblo, región, } \\
\text { continente). } \\
\text { Continúan presentes las teorías } \\
1,2,3,4 \text { y } 5 \text {. }\end{array}$ \\
\hline \multicolumn{3}{|c|}{ ACTITUDES POSITIVAS Y PREJUICIOS ASOCIADOS AL RACISMO } \\
\hline $\begin{array}{l}\text { Autoadscripción, actividades y } \\
\text { atributos positivos. }\end{array}$ & \multicolumn{2}{|c|}{$\begin{array}{l}\text { Prejuicios, estereotipos y lo negro como estigma. } \\
\text { Alusión a discriminación. } \\
\text { Empleo de la noción de raza. } \\
\text { Empatía. }\end{array}$} \\
\hline
\end{tabular}

Fuente: Elaboración propia.

Nota: Los elementos de niños de menor edad continúan entre aquellos de mayor edad. 


\section{Pautas metodológicas para combatir el racismo en localidades afromexicanas}

Las siguientes propuestas buscan guiar intervenciones que tengan como objetivo disminuir o eliminar estereotipos, estigmas, prejuicios e ideas racistas, así como prácticas discriminatorias hacia las personas "negras" o afromexicanas $^{11}$. Se trata de pautas que se han pensado para localidades con población afrodescendiente por lo que se deberán adecuar las estrategias a las características de cada espacio. El primer paso será indagar si la representación social de los niños sobre lo negro y la población afrodescendiente, así como la presencia de prejuicios y actitudes positivas hacia ella, coincide en términos generales con lo expuesto aquí, para lo cual recomiendo recurrir a estrategias etnográficas, así como a talleres que fomenten la libre expresión de ideas y conocimientos, y que representen un espacio de respeto mutuo. Después, sugiero ajustar estas pautas de acuerdo a la edad y el grado escolar de los participantes.

1. Recuperación de aspectos positivos sobre el lugar, concepto que hace referencia a un espacio construido social, ideológica y ecológicamente, como se explicó previamente.

2. Anclar la representación social de las personas "negras" al lugar que previamente ha sido construido como positivo, con una perspectiva histórica.

3. Informar sobre los nombres de la representación social de las personas negras, ya que para Moscovici $(2014$, p.36) "la representación es básicamente un sistema de clasificación y denotación de asignación de categorías y nombres". Además, "nombrar, comparar, asimilar o clasificar supone siempre un juicio que revela algo de la teoría que uno se hace del objeto clasificado" (Jodelet, 1984, p.492). Así, recomiendo utilizar las diferentes palabras que los propios niños utilicen para nombrar la categoría que hace referencia a las personas y poblaciones "negras", tales como "morenas" y "prietas", e incluir otros términos significativos a nivel regional, nacional e internacional, como "afromexicanos" y "afrodescendientes".

4. Favorecer el mecanismo de objetivación de la representación social de las personas "negras"/"afromexicanas" de manera positiva, buscando disminuir el prejuicio, estereotipo y estigma. Por ejemplo:

a. Presentar representaciones gráficas, manipular objetos y construir materiales a partir de actividades compartidas y juegos, que favorezcan la formación de imágenes (conjuntos de significados) positivos sobre las personas "negras"/"afromexicanas".

b. Proporcionar información que clarifique las teorías sobre lo negro, para favorecer la comprensión y el respeto a la diversidad humana, destacando la información histórica y actual sobre las poblaciones afrodescendientes.

c. En la representación gráfica de las personas "negras" o "afromexicanas" es recomendable favorecer el uso de varios colores que los propios niños reconozcan como característicos de las personas negras, morenas, afromexicanas o afrodescendientes, procurando resignificar lo negro mediante la eliminación del estigma.

d. En las actividades que no impliquen una representación gráfica es conveniente insistir en aquellas actividades, atributos 
y características positivas diferentes al tono de piel, aunque sin desincentivar la asociación con la fenovariabilidad (o fenotipo).

5. Guiar a los niños para que diseñen y desarrollen campañas contra el racismo en su localidad, lo que les permitirá aprender de manera significativa y situada, así como incidir en su propio contexto para lograr una sociedad más justa e igualitaria.

a. Generar un espacio de reflexión acerca del racismo, la discriminación racista, los prejuicios, estereotipos y estigmas, favoreciendo la expresión de experiencias que los niños recuerden para generar empatía; aunque evitando revictimizar - generar lástima hacia las personas que enfrentan este tipo de prácticas. En cambio, se busca incentivar su reflexión crítica para identificar estos fenómenos, conozcan por qué deben evitarse y cómo pueden combatirse.

b. En aquellos casos en que se emplee la noción de raza, resulta recomendable clarificar los motivos biológicos por los cuales las razas humanas no existen, explicando qué es la variación biológica humana, así como el hecho de que la fenovariabilidad es cambiante. Igualmente, explicar acerca de la diversidad cultural e histórica procurando erradicar el concepto de raza ${ }^{12}$.

\section{Consideraciones finales}

Los niños participan activamente en la construcción de sus conocimientos y de ninguna manera son receptáculos o repetidores de las representaciones sociales adultas. La antropóloga y psicóloga, Christina Toren (1993), propuso un modelo antropológico de la mente que demanda centrarse en los niños -considerados al mismo tiempo sujetos y objetos de la historia-, así como en los procesos mediante los cuales constituyen su conocimiento sobre el mundo. Ella considera esencial estudiar los procesos cognoscitivos de los niños, pero sin olvidar las relaciones de los demás, lo cual implica comprender cómo las personas toman por sentado los significados, conceptos y prácticas que ellos mismos crearon. Al respecto, es pertinente recordar que las operaciones y procesos interpersonales no se transmiten o copian en el plano intrapsicológico, sino que se transforman, modifican y reconstruyen para ser interiorizados y, a su vez, las personas colaboran en su co-construcción mediante su interacción con otros (Santamaría, 2005). Además, "los significados de las palabras son formaciones dinámicas, no estáticas" (Vygotsky, 2015, pp. 284-285), de modo que deben ser comprendidos como procesos que se transforman.

En este artículo mostré aspectos centrales de la representación social de lo negro, que construyen niñas y niños de pueblos afromexicanos, como las categorías, imágenes y teorías. Igualmente, identifiqué actitudes positivas hacia las personas negras, reflejadas en autoadscripción, empatía y la asociación con actividades y atributos positivos. Otro componente significativo de esta representación social, fue el racismo estructural e histórico que se expresó en prejuicios y estereotipos, la construcción de lo negro como un estigma, el uso del concepto de raza y la alusión a los actos de discriminación que enfrentan las personas negras. Aunque en términos generales ello puede afirmarse al 
respecto de los niños de las tres localidades de estudio, es importante considerar las particularidades de cada una, así como el papel que tiene la edad y el grado escolar de los niños, como se resumió en el cuadro 3.

Es evidente el papel que tiene el lugar, en tanto construcción social, ideológica, ecológica e histórica del espacio. Por un lado, el efectolugar (Hoffmann, 2007a) muestra la importancia de las características del pueblo, su posición y sus interacciones con otras escalas en la construcción de modelos étnicos y de procesos de identificación a nivel local. Ello explica las diferencias de la representación social de lo negro entre un caso y otro, mismas que he procurado mencionar, aunque el propósito no haya sido analizar cada uno detalladamente (Masferrer, 2014, 2017). Por otro lado, el lugar tiene un papel central en la representación social de las personas negras ya que una de las teorías infantiles que he mostrado remite a lo negro como una característica general de la población de un espacio de pertenencia que es construido socialmente como un lugar. Dado que el lugar suele ser significativo en los procesos de identificación de los niños (Masferrer, 2014), podemos decir que mientras más coincida el sentido de lugar con el espacio que se asocia a lo negro, mayor será la autoidentificación. De allí que algunas de las pautas metodológicas se centren en este aspecto.

Finalmente, quisiera subrayar que investigar cómo los niños construyen, a lo largo del tiempo, las ideas claves que los adultos usan permite entender cómo estas nociones se transforman históricamente en el proceso mismo de su constitución (Toren, 1993). Por tanto, las propuestas que busquen modificar estas nociones deberán tomar en cuenta su proceso de internalización, pero también los complejos procesos históricos, sociales, económicos y políticos que permiten la perpetuación de estructuras macrosociales racistas que violentan los derechos humanos de ciertas personas y poblaciones. El análisis de la representación social de niños de localidades afromexicanas sobre las personas negras y su vinculación con el prejuicio racista, espera conducirnos a generar propuestas metodológicas y acciones para combatir el racismo. 


\section{Notas}

${ }^{1}$ En este artículo, la frase "pueblos afromexicanos" hace referencia a localidades geoestadísticas con presencia de personas que se reconocen como "negras", "morenas", "afromestizas", "afromexicanas" o "afrodescendientes. La palabra "pueblo" se emplea por ser la más utilizada por niñas y niños de estas poblaciones y se refiere principalmente al espacio en el cual habita un conjunto de personas, el cual recibe un nombre y es reconocido tanto por una disposición legal y político administrativa como por la costumbre (INEGI, 2010).

${ }^{2}$ Este artículo se basa en los resultados de mis investigaciones de titulación (Masferrer, 2014, 2017).

${ }^{3}$ Las edades aproximadas de los grados escolares son: Primero, 6-7 años; Segundo, 7-8 años; Tercero, 8-9 años; Cuarto, 9-10 años; Quinto, 10-11 años; Sexto 11-12 años.

${ }^{4}$ Para más información sobre la metodología, véase: Masferrer 2014 y 2017.

${ }^{5}$ Es posible que anteriormente hubiera una ruta importante en sentido opuesto, es decir, de Collantes o Puerto Minizo hacia el interior, pasando por Morelos y Huazolotitlán hacia Huaxpaltepec y otros lugares como Pinotepa (Masferrer, 2014).

${ }^{6}$ Hoffmann (2007a) retoma el concepto "mestizo" de Elisabeth Cunin para referirse a "la capacidad de conocer, movilizar, aplicar las reglas y los valores requeridos en cada situación, de pasar de un marco normativo a otro, de definir el papel de sí mismo y el de los otros de manera independiente" (p. 104).

7 Aunque se ha demostrado que biológicamente las razas humanas no existen, el modelo étnico se construye a partir de este concepto en tanto construcción social, cultural, política e histórica. La noción de "raza" se explica en las páginas 17, 18 y 19 de este artículo; por "racial" o "características raciales" se comprende aquello que se deriva de esta noción, la cual constituye una manera de clasificar la diversidad humana que responde a un conjunto de procesos históricos, socioculturales y políticos, y no corresponde a ninguna realidad biológica.

\section{Referencias bibliográficas}

Aguirre, G. (1989). Cuijla. Esbozo etnográfico de un pueblo negro. México: FCE.

Allport, G. (1954). The nature of prejudice. Cambridge: AddisonWesley Publishing Company.

Billig, M. (1985). Racismo, prejuicios y discriminación. En Moscovici S. (Ed.), Psicología social II. Pensamiento y vida social. Psicología social y problemas sociales, (pp. 575-600). Vol. II. Barcelona: Paidós.

Butz, D. \& Eyles, J. (1997). Reconceptualizing senses of place: social relations, ideology and ecology. Geography Annuary, 79B (1), 1-25.

Carballera, Y. \& Sastre, M.A. (1991). Usos de sery estar. Revisión
${ }^{8}$ Erving Goffman (2006, p. 61) explica que "los signos que transmiten información social varían según sean o no congénitos y, en caso de que no lo sean, según que, una vez empleados, se conviertan o no en una parte permanente de la persona". El tono o color de piel, es un signo congénito y permanente, a pesar de que en cada situación y contextos social e histórico puede tener significados diferentes (Masferrer, 2017).

${ }^{9}$ Las principales preguntas para indagar acerca de las teorías sobre las personas negras fueron: ¿qué significa ser negro o moreno? ¿Qué les viene a la mente cuando digo personas negras? ¿Por qué la gente es negra, morena o indígena? ¿Cómo se puede saber si una persona es negra? ¿Cómo se puede saber si alguien es indígena? ¿Tú cómo te consideras? Asimismo, en algunos casos se prestó atención a la manera en que los niños se expresaban a este respecto, en comunicaciones entre pares con mínima mediación de mi parte.

${ }^{10} \mathrm{Advierten}$ que la diferencia entre estos verbos también radica en dónde se centre la atención: "al final del acto o en su transcurso" (Carballera \& Sastre, 1991, p.301). Concluyen: "La cualidad que se atribuye a un sujeto se puede enunciar en sí misma sin atender a su origen, o se puede considerar como el resultado de una acción o cambio. En el primer caso se usa el verbo ser porque interesa su duración o permanencia; por tanto, es imperfectiva: el jarrón es negro. En el segundo se usa el verbo estar porque se percibe como resultante de alguna transformación, por tanto, es perfectiva; transformación que puede ser real: el jarrón está roto, o supuesta, sin que se haya producido: el jarrón está intacto (porque se piensa en la posibilidad de algún accidente)" (Carballera \& Sastre, 1991, p.301).

${ }^{11}$ Una explicación más detallada de estas pautas puede consultarse en Masferrer, 2017, pp. 179-184.

${ }^{12}$ Como ya se dijo, "no hay que confundir la presencia o ausencia de una palabra con la presencia o ausencia de un concepto" (Restrepo, 2012, p.155). de la gramática y constatación de la realidad lingüística. En Montesa, S. \& Garrido A., Actas III. Congreso Internacional Asociación para la Enseñanza del Español como Lengua Extranjera. pp. 299-313, Málaga: AEELE.

Castillo, A. (2000). El papel de los estereotipos en las relaciones interétnicas: mixtecos, mestizos y afromestizos en Pinotepa Nacional, Oaxaca. (Tesis inédita de licenciatura). México: ENAH.

Castorina, J. \& Kaplan, C. (2003). Las representaciones sociales: problemas teóricos y desafíos educativos. En Castorina J. (comp.), Representaciones sociales (pp. 9-28). Barcelona: Paidós,

Comisión Nacional para el Desarrollo de los Pueblos Indígenas 
(CDI). (2012). Informe final de la consulta para la identificación de comunidades afrodescendientes de México. México: CDI.

Consejo Nacional para Prevenir la Discriminación (Conapred) (2008). Curso Taller Prohibido Discriminar ( $2^{a}$ edición corregida y aumentada). México: Conapred.

Díaz, C. (2003). Queridato, matrifocalidad y crianza entre los afromestizos de la Costa Chica. México: Conaculta.

Duveen, G. \& Lloyd, B. (2003). Las representaciones sociales como una perspectiva de la psicología social. En Castorina, J. (comp.), Representaciones sociales (29-40). Barcelona: Paidós.

Essed, P. (1991). Understanding Everyday Racism. An interdisciplinary Theory. California: Sage Publications.

Farr, R. (1984). Las representaciones sociales. En Moscovici, S. (comp.), Psicología Social II. Pensamiento y vida social (495-506). Barcelona: Paidós.

Goffman, E. (2006). Estigma. La identidad deteriorada. Buenos Aires: Amorrortu.

González, C. (2011). De la casta a la raza. El concepto de raza: un singular colectivo de la modernidad. México, 1750-1780. Historia Mexicana, LX(3), 1491-1525.

Hall, S. (2010). Sin garantías. Trayectorias y problemáticas en estudios culturales, (Restrepo, E., Walsh, C. \& Vich, V., eds.). Popayán: PUJ/IEP/UASB/Envión Eds.

Hernández, G. (2006). Paradigmas en psicología de la educación. México: Paidós.

Hoffmann, O. (2007a). De las tres razas al mestizaje: diversidad de las representaciones colectivas acerca de lo negro en México (Veracruz y Costa Chica). Diario de Campo, 42, 98-109.

Hoffmann, O. \& Lara, G. (2012). Reivindicación afromexicana: formas de organización de la movilización negra en México. En Becerra, M., Buffa, D., Noufouri, H. \& Ayala, M. (comps.), Las poblaciones afrodescendientes de América Latina y el Caribe. Pasado, presente y perspectivas desde el siglo XXI (25-46). Córdoba: UNTF/ UNC/Cátedra Unesco.

(2007b). Las narrativas de la diferencia étnico-racial en la Costa Chica, México. Una perspectiva geográfica. En Hoffmann, O. \& Rodríguez, M. (eds.), Los retos de la diferencia, actores de la multiculturalidad entre México y Colombia. pp. 363-397. México: CEMCA/CIESAS/ICANH/IRD.

INEGI. (2010). Conurbaciones y fusiones de localidades, Aguascalientes: INEGI, Recuperado de www.inegi.org.mx/geo/ contenidos/geoestadistica/doc/conur_fusion.pdf, noviembre 2017.

(2017). Encuesta Intercensal 2015. Perfil sociodemográfico de la población afrodescendiente en México. México: Conapred, CNDH, INEGI.

(2017). Datos por área geográfica. Recuperado de www. beta.inegi.org.mx, julio 2017.

(2017). Mapa digital de México. Recuperado de gaia. inegi.org.mx/mdm6, julio 2017.

James, A. \& Prout, A. (1997). Constructing and Reconstructing Childhood. Contemporary Issues in the Sociological Study of Childhood. Bristol: Falmer Press
Jodelet, D. (1984). La representación social: fenómenos, concepto y teoría. En Moscovici, S. (comp.), Psicología Social II. Pensamiento y vida social (469-494). Barcelona: Paidós.

Lara, G. (2010). Una corriente etnopolítica en la Costa Chica, México (1980-2000). En Hoffmann, O. (coord.), Política e identidad. Afrodescendientes en México y América Central (307-334), México: INAH/UNAM/IRD.

(2012). Espacios, sociedades y acción institucional en la Costa de Oaxaca. Oaxaca: Conaculta/Gobierno del Estado de Oaxaca/Fundación Alfredo Harp Helú Oaxaca.

Masferrer, C. (2013). Muleke, negritas y mulatillos. Niñez, familia y redes sociales de los esclavos de origen africano en la Ciudad de México, siglo XVII. México: INAH.

(2014). Aquí antes se llamaba Poza Verde. Conocimientos de niños de la Costa Chica sobre su pueblo y lo negro. (Tesis inédita de maestría). México: CIESAS.

(2016a). Muchitos, melarchía y respeto. Niñez, enfermedad y relaciones intergeneracionales en un pueblo afromexicano de la Costa de Oaxaca, Anales de Antropología. Revista del Instituto de Investigaciones Antropológicas, 50(2), 216-231.

(2016b). "Yo no me siento contigo". Educación y racismo en pueblos afromexicanos. Diálogos sobre educación. Temas actuales en investigación educativa, 7(13), 1-17.

(2017). La representación social de niños de una localidad afromexicana de Oaxaca sobre las personas "negras". (Tesis inedita de licenciatura). México: UNAM.

Massey, D. (1994). From Space, Place and Gender. Minneapolis: University of Minnesota Press.

Moreno, M. (2012). "Yo nunca he tenido la necesidad de nombrarme": reconociendo el racismo y el mestizaje en México. En Castellanos, A. y Landázuri, G. Racismos y otras formas de intolerancia. De norte a sur en América Latina. pp. 15-48. México: UAM.

Moscovici, S. (2014). El fenómeno de las representaciones sociales. El Alma Pública. Revista desdisciplinada de psicología social, 7(14), 9-72.

Plous, S. (2003). The Psychology of Prejudice, Stereotyping and Discrimination: An Overview. En Plous S. (Ed.), Understanding Prejudice and Discrimination. pp. 3-48. Nueva York: McGraw-Hill.

Quecha, C. (2011a). Cuando los padres se van: Infancia y migración en la Costa Chica de Oaxaca. (Tesis de doctorado). México: UNAM. (2011b). La niñez y juventud afrodescendiente en el México de hoy. Experiencias a partir de la migración México-Estados Unidos. Cuicuilco, 18(51), 63-82.

(2015). Niñas cuidadoras en contextos migratorios. El caso de las poblaciones afrodescendientes en la Costa Chica de Oaxaca. Cuicuilco, 22(64), 155-175.

(2016). Familia, infancia y migración: un análisis antropológico en la Costa Chica de Oaxaca. México: UNAM.

Qvortrup, J. (2011). Nove teses sobre a infância como um fenômeno social. Pro-Posições, 22(1), 199-211.

Ramírez, C. (2007). De genes, razas y racismo (parte I). Revista del Instituto Nacional de Higiene Rafael Rangel, 38(1), 1-5. 
(2009). De genes, razas y racismo (parte II). Revista del Instituto Nacional de Higiene Rafael Rangel, 40(2), 1-4.

Restrepo, E. (2012). Intervenciones en teoría cultural. Popayán: Universidad del Cauca.

Santamaría, A. (2005). La noción de interiorización desde una visión cultural del desarrollo. En Cubero, M. \& Ramírez, J. (comps.), Vygotsky y la psicología contemporánea. pp. 81-111. Buenos Aires: Miño y Dávila.

Szulc, A. (2006). Antropología y niñez: de la omisión a las 'culturas infantiles'. En Wilde, G. \& Schamber P. (comps.), Culturas, comunidades y procesos urbanos contemporáneos (25-50). Misiones: Ediciones SB.

Toren, C. (1993). Making History: The Significance of Childhood Cognition for a Comparative Anthropology of Mind. Man, New Series, 28(3), 461-478.

Velázquez, M. \& Hoffmann, O. (2007). Investigaciones sobre africanos y afrodescendientes en México: acuerdos y consideraciones desde la historia y la antropología. Diario de Campo, (91), 62-68.

Velázquez, M. (2016). Balances y retos de los estudios antropológicos sobre poblaciones afrodescendientes en México. Anales de Antropología. Revista del Instituto de Investigaciones Antropológicas, 50(2), 177-187.

Velázquez, M. \& Iturralde, G. (2016). Afromexicanos: reflexiones sobre las dinámicas del reconocimiento. Anales de Antropología. Revista del Instituto de Investigaciones Antropológicas, 50(2), 232-246.

Vygotski, L. (2006). El desarrollo de los procesos psicológicos superiores. Barcelona: Crítica.

(2015). Pensamiento y lenguaje. México: Paidós.

Wieviorka, M. (2009). El racismo: una introducción. Barcelona: Gedisa.

Worchel, S., Cooper, J., Goethals, G. \&, Olson, J. (2002). Psicología social, México: Thomson. 